\title{
ORIGEN, VÍAS DE PENETRACIÓN Y EXPANSIÓN DE CRUCES Y CRUCEROS EN LA PENÍNSULA IBÉRICA
}

\author{
POR \\ Marta Plaza Beltrán \\ Profesora de la Facultad de Bellas Artes, Universidad Complutense de Madrid
}

\section{RESUMEN}

¿Cómo nacen las cruces monumentales que nosotros conocemos? El artículo que nos ocupa pretende dar a conocer el origen de las cruces de piedra que vemos distribuidas por toda la geografía española, consideradas todas ellas elementos artísticos con una fuerte carga simbólica, social y cultural.

La doctrina cristiana, utilizó primero el signo de la cruz para la consagración de lugares o elementos pertenecientes a antiguos cultos paganos y más tarde, de forma material, la situó en estos puntos (sobre dólmenes, menhires, miliarios; en los caminos, puentes, fuentes o montes), con o sin pedestal, construida de madera o de piedra, con diferentes formas y características.

PalABRAS ClaVE: Patrimonio cultural, Etnografía, Escultura, Religiosidad popular, Cruces, Cruceros, Piedra.

\section{ORIGIN, WAY OF PENETRATION AND EXPANSION OF CROSSINGS AND CRUISES IN THE IBERIAN PENINSULA}

\section{ABSTRACT}

This article aim to clarify the origin of the crosses made of stone spread all over the Spanish geography. These elements were considered as artistic elements and had an simbolic, social and cultural importance.

Christian doctrine employed the symbol of the cross in order to christianize certain places or items belonging to former pagan cults.

Christianity placed crosses on dolmens, menhirs, paths, bridges, fountains and mountains, with or without pedestal, made either of wood or stone, with different forms and features. 
KEY WORDS: Cultural heritage, Ethnography, Sculpture, Popular religiosity, Crossed, Cruiser, Stone

\author{
Recibido/received 01-10-2010 \\ Aceptado/Accepted 04-03-2012
}

\title{
INTRODUCCIÓN
}

La cruz - inscrita, pintada o esculpida - es uno de los símbolos más antiguos creados por el hombre. Como cruz sencilla o monumental, la encontramos formando parte del paisaje en toda la geografía española, ya sea presidiendo atrios de iglesias, situada en el centro de plazas, en los cruces de caminos, en altozanos o en medio de los campos. Se trata de un elemento de culto ancestral que ha llegado hasta nuestros días para trasmitirnos y legarnos el sentir religioso e histórico de nuestros antepasados.

Así, a través de diversos materiales - piedra, madera, hierro- y por medio de formas y caracteres diversos (sencilla, labrada, hincada, sobre pedestal, con capilla, con imágenes, etc.), la cruz se ha ido adaptando a las creencias de cada lugar, acompañando y cobijando a viajeros y caminantes.

\section{Origen y nacimiento de las cruces altas}

El origen de nuestras cruces de piedra debemos buscarlo en las Islas Británicas, en el arte celta de esta región. Las primeras cruces de esta categoría que se erigieron fueron las llamadas cruces altas (también llamadas outas o hincadas) irlandesas y anglosajonas ${ }^{1}$ durante los siglos VII y VIII, entre las que destacan dos de las más antiguas, la cruz escocesa de Ruthwell ${ }^{2}$ y la inglesa de Bewcastle $^{3}$ ambas datadas en el siglo vil.

${ }^{1}$ Las cruces anglosajonas fueron a su vez las precursoras de las irlandesas.

${ }^{2}$ Antigua cruz de piedra datada en el siglo vII. Originalmente estaba situada en el cementerio de Ruthwell, pero durante una reforma de rehabilitación de la iglesia se colocó en su interior. En el brazo vertical inferior podemos ver escenas de las escrituras y de la mitología anglosajona; también observamos textos bíblicos y un fragmento del poema inglés The Dream of the rood (El Sueño de la Cruz) en alfabeto rúnico que relata el sueño de un poeta que encontró un gran árbol decorado con joyas y que representaba la cruz de Cristo.

${ }^{3}$ Cruz fragmentada de la que sólo se conserva el brazo vertical, ricamente decorado con entrelazados y representaciones de santos. En el mausoleo de Catherine Losh, de esta misma ciudad, existe una reproducción con todos sus elementos reconstruidos y datada en 1834.

Hispania Sacra, LXV

131, enero-junio 2013, 7-28, ISSN: 0018-215-X, doi: 10.3989/hs.2013.001 
El hecho de que Irlanda no sufriera de cerca la invasión del Imperio Romano favoreció que este pueblo conservara muchas de sus tradiciones antiguas, tanto sociales como culturales. A este factor habría que unir la lenta y progresiva conversión al cristianismo de su sociedad en unos siglos de peligro caracterizados por las invasiones bárbaras. Todo ello hizo que los monjes celtas de esta región, ajenos a los aconteceres exteriores, continuaran con su vida monástica de recogimiento y guarda de la riqueza espiritual y artística que, más tarde, se difundirá por la Europa occidental y llegará a nuestra Península a través del ciclo Carolingio.

La influencia del arte celta de las Islas Británicas sobre las cruces del arte continental europeo queda patente en dos hechos importantes: por un lado el nacimiento de las cruces altas en Europa como asimilación de los menhires y por otro, el renacer de una escultura desde las cruces anglo-irlandesas que posteriormente se desarrollará y florecerá con el arte románico. Estas teorías han sido apoyadas por autores como M. Stokes ${ }^{4} \mathrm{o}$ G. B. Brown ${ }^{5}$ y más tarde por el medievalista A. K. Porter quien, basándose en algunas escenas representadas en la escultura románica, afirma que tienen sus antecedentes en las cruces inglesas de los siglos VII y VIII, y en las irlandesas de los siglos IX y x. ${ }^{6}$ Contemporáneo a este último tenemos a F. Henry que, coincidiendo en algunas afirmaciones con el anterior sobre el origen de las cruces, añade su teoría sobre los escultores irlandeses que esculpían en piedra los motivos que en el arte carolingio sólo realizaban en marfil, como podían ser las cruces. ${ }^{7}$ A este respecto cabe señalar que la dificultad y rudeza de la labra en piedra no exime a estas cruces de tener una rica y delicada decoración geométrica de entrelazados, con claras reminiscencias musulmanas. ${ }^{8}$

Hasta aquí venimos hablando de las cruces altas o cruces hincadas con un posible origen en las Islas Británicas, pero también es necesario mencionar las cruces monumentales provistas de gradas, conjuntos erigidos sobre unos escalones y con otros elementos que le son característicos y que datan del siglo XIV, cuyo origen podemos encontrarlo en las cruces levantadas en los campos germanos y que se introducen en España a través del ciclo Bretón. ${ }^{9}$

\footnotetext{
${ }^{4}$ Stokes, M. 2004. Early Christian Art in Ireland. Montana: Kessinger Publishing.

${ }^{5}$ Brown, G. B. 1921. The Arts in Early England: The Ruthwell and Bewcastle Crosses. New York: Dutton.

${ }^{6}$ Kingsley Porter, A. 1935. The crosses and culture of Ireland. New Haven: Yale University Press.

${ }^{7}$ Henry, F. 1930. «Les origines de 1'iconographie irlandesa». Revue Archéologique XXXII: 89-109.

${ }^{8} \mathrm{La}$ influencia oriental en las decoraciones de las cruces irlandesas es muy significativa debido a la conquista musulmana de Siria y Egipto, hecho que provocó la emigración de muchos monjes hacia los monasterios de su misma orden en Irlanda.

${ }^{9}$ Entre las cruces bretonas podemos mencionar ejemplos importantes como las cruces de Tremaouezan, Kelecq-Kerhuou, Plouider, Lesneven, Cleder, Plouaeventer, etc. destacando la de Plourivo por considerarse la más antigua de Bretaña junto a las de Lancerf.
} 
LA EVANGELIZACIÓN DE MONJES BRETONES E IRLANDESES COMO PROCESO INTRODUCTOR DE LAS CRUCES ALTAS EN LA PENÍNSULA IBÉRICA

Las primeras cruces que llegan a la península Ibérica datan del siglo vII, periodo en el que muchos monjes bretones e irlandeses se instalaron en la zona norte con la intención de evangelizar este territorio. Aunque cabe señalar a este respecto que mucho antes de esta fecha, ya existían asentamientos bretones con una estructura eclesiástica formada, ${ }^{10}$ pues en el siglo vI, tras el Concilio de Lugo celebrado el año 567, se reconoce oficialmente esta organización y se crea la sede episcopal Britonia o Bretoña, ${ }^{11}$ con monasterio y obispo propio. A partir de esta fecha es cuando se inician los movimientos de monjes hacia nuestra tierra y los asentamientos se van extendiendo por todo el norte peninsular, entre los que destaca la iglesia de San Martín de Mondoñedo (situada al norte de Lugo) o el cercano monasterio Maximi o de Máximo.

La difusión de la religión por parte de estos monjes se vio favorecida por las comunicaciones marítimas, ya que las comunidades del norte peninsular mantuvieron un continuo contacto tanto con la sede de Armorica - Bretaña francesa - como con la de las Islas Británicas. Este hecho queda de manifiesto en un manuscrito irlandés medieval, el Libro de Leinster, ${ }^{12}$ donde se narra el relato de navegación de una embarcación llamada Ui Corra (Immram Curaig Ua Corra) ${ }^{13}$ Según datos aportados por W. Stokes, esta barca, tipo curragh o coracle,$^{14}$ llegó a las costas gallegas con «nueve hombres a bordo, entre ellos un obispo y un prelado» para fundar una iglesia en esta tierra. ${ }^{15}$

Del siglo vir podemos datar la cruz de Pao da Vella, erigida en los montes de Buio (Lugo) ${ }^{16}$ y que el estudioso Castelao asocia con las cruces levantadas en tierras bretonas por monjes procedentes de las Islas Británicas. ${ }^{17} \mathrm{Se}$ trata de una cruz hincada con los brazos muy poco pronunciados, similar a las que se alzaban en el centro de Europa.

\footnotetext{
${ }^{10}$ Algunos autores, como Antonio García García, consideran el siglo iv como la época en la que llegaron los bretones a Galicia. Véase García García, A. 1986. «Ecclesia Britoniensis». Estudios Mindonienses 2: 121-134.

${ }^{11}$ Localizada en la actual Santa María de Bretoña, a $15 \mathrm{Km}$ de San Martín de Mondoñedo (Lugo).

${ }^{12}$ Manuscrito medieval irlandés basado en un texto del siglo vIII, recopilado en 1160 y conservado actualmente en el Trinity Collage de Dublín. Entre sus contenidos está el Libro de las invasiones irlandesas donde se narran detalladamente estas incursiones.

${ }^{13}$ Alonso Romero, F. 1991. Santos e barcos de pedra: 55-57. Vigo: Xerais.

${ }^{14}$ Tipo de embarcación fabricada en madera con tres capas de cuero superpuestas, típica de Irlanda y Escocia.

${ }^{15}$ Stokes, W. 1893. «The voyage of the Hui Corra». Revue Celtique XIV: 61.

${ }^{16}$ Situada en el límite entre los municipios de Viveiro, Xove, Alfoz y Cervo.

${ }^{17}$ Rodríguez Castelao, A. 1984. As cruces de pedra na Galiza: 20-28. Facsímil de 1950. Vigo: Galaxia.
} 
Peregrinaciones a Santiago. Vías de comunicación entre Europa y la Península IBÉRICA

El origen del Camino de Santiago es muy antiguo, pues se trata de un camino transitado por todas las civilizaciones a lo largo de la historia, orientado hacia el punto donde se pone el sol. De este modo, anterior al mismo, ya existió la ruta que iba desde Roma hasta el final de la tierra (Finis Terrae) fundamentado en la idea de una tierra plana.

Tras el descubrimiento de la tumba del Apóstol Santiago el Mayor en Compostela, aproximadamente en el año 820, se crea una ruta de peregrinación a este lugar con objeto de venerar sus reliquias. Se convierte para los cristianos en una de las tres peregrinaciones más importantes, junto a la de Roma y Jerusalén. Desde este hallazgo, las referencias al cuerpo del Apóstol en Santiago se van sucediendo de forma progresiva $;{ }^{18}$ entre ellas destaca el Códice Calixtino o Liber Sancti Jacobi, datado en el siglo XII, formado por cinco libros, todos ellos de temática jacobea y donde se pueden encontrar sermones, milagros jacobeos, itinerarios, la narración del traslado del cuerpo de Santiago o la crónica que describe la entrada de Carlomagno en la Península con objeto de liberarla del dominio musulmán. ${ }^{19}$

Hasta la segunda mitad del siglo xi el Camino de Santiago tenía un carácter selectivo, pues solía ser gente acaudalada y cercana al poder eclesiástico o civil (obispos, abades, reyes, condes, duques, etc.) los que acudían como peregrinos a Compostela. A partir de esta época las peregrinaciones se hacen cada vez más importantes y alcanzan su apogeo durante el siglo XII.

Existieron numerosas rutas de entrada a la Península incluso, dentro de ella, varios caminos hasta llegar a Compostela. El continuo movimiento de peregrinos a lo largo de las distintas rutas supuso un fuerte desarrollo económico y cultural para la península Ibérica. De este modo, los caminos de peregrinación se convierten en una de las principales vías de entrada en nuestro territorio de influencias artísticas y religiosas procedentes del resto de Europa. Parafraseando a J. Burgoa, podemos decir que el Camino de Santiago «es un hecho histórico, espiritual y cultural que se puede entender y contemplar desde diferentes perspectivas». ${ }^{20}$

\footnotetext{
${ }^{18}$ Díaz y Díaz, M. 1965. «La literatura jacobea anterior al Códice Calixtino». Compostellanum 10, 4: $283-305$.

${ }^{19}$ Moralejo A. 2004. Liber Sancti Jacobi, trad. Santiago de Compostela: Xerencia de Promocion do Camiño de Santiago.

${ }^{20}$ Burgoa Fernández J. J. 2003. Los cruceros, el patrimonio etnográfico y el arte popular: 107. La Coruña: edicios do Castro.
} 
Tras el importante auge que sufre la ruta de Santiago en el siglo XII, se levantan numerosas cruces a lo largo de dicho camino y se cristianizan antiguos miliarios como señales de esta vía de peregrinación. Las primeras cruces no tenían todavía imágenes talladas ni columna, se trataba de cruces sencillas cruces hincadas - con el brazo inferior más largo situado sobre unas gradas. Según la tradición, el primer lugar donde se erigió un crucero (coronado con cruces de madera) fue en la subida al monte Pedroso, coincidiendo con la llegada de San Francisco a Compostela. También se habla de la cruz levantada por Carlomagno cuando entró con sus tropas en España atravesando los Pirineos por el puerto de Cise ${ }^{21}$ conocida como Cruz de Carlos y mencionada en una carta episcopal de Baiona del año 980.22 Ya del siglo XIv es la Cruz de Roncesvalles (Navarra), situada junto a una capilla dedicada al apóstol Santiago. ${ }^{23}$ Con el paso del tiempo, las cruces góticas fueron sustituyendo a estas cruces simples conservando, en algunos casos, elementos anteriores. Podemos decir, por lo tanto, que las cruces de peregrinos levantadas en origen fueron reemplazadas o transformadas en las cruces monumentales que ahora conocemos como calvarios o cruceros. ${ }^{24}$

La influencia que tuvieron los cruceros bretones e irlandeses sobre nuestras cruces a través del Camino de Santiago es innegable, pues fueron muchos los viajeros procedentes de Europa que llegaron a Santiago siguiendo este trayecto. A este respecto, hay que señalar que la influencia de los bretones es mayor que la de los irlandeses, pues estos últimos se trasladaban en barco hasta los puertos del Golfo de Artabro (La Coruña) y desde allí realizaban la ruta a través del Camino Ingles, más corto que el Camino Francés, seguido por los primeros. Según lo expuesto, el Camino Francés de peregrinación a Santiago constituyó la vía de entrada en España de los cruceros bretones y franceses, mientras que el Camino Inglés lo hizo con los irlandeses. Muestra de ello es la existencia en el País Vasco de muchos cruceros semejantes a los calvarios franceses del siglo Xv, como la cruz de término de Zarautz o la de Durango (conocida como Cruz de Kurutziaga), con estatuas esculpidas en ambas caras y una serpiente enrollada en el varal (posiblemente erigida por la existencia de un foco de protestantismo en el País Vasco).

Junto a los cruceros, son numerosos los elementos auxiliares ligados a la ruta jacobea (fuentes, puentes, hospitales, ermitas, capillas, monasterios, mercados, casas solariegas, etc.), los cuales han otorgado un importante impulso

\footnotetext{
${ }^{21}$ París, G. 2000. Légendes du Moyen Age: 31-41. Barcelona: MRA.

${ }^{22}$ Rodríguez Castelao, A. 1984: 84.

${ }^{23}$ La datación del siglo XIv corresponde únicamente a la cruz, el fuste es de factura posterior.

${ }^{24}$ Los cruceros, propiamente dichos, no llegan a la Península hasta el siglo XIV.
} 
socioeconómico a muchas poblaciones situadas en su recorrido. ${ }^{25}$ De este modo, el desarrollo hospitalero del Camino de Santiago tuvo lugar gracias a los benedictinos que, como veremos más adelante, fueron los encargados de abrir hospederías y hospitales a lo largo del mismo con la intención de acoger a los peregrinos, pues según establecían sus reglas, la hospitalidad debía ser la primera virtud de los mojes.

Pero además de estas construcciones encontramos numerosos miliarios situados al pie de las calzadas, ${ }^{26}$ elementos pétreos que sirvieron a los romanos para indicar o marcar los caminos y actualmente considerados como los predecesores de las denominadas Cruces de Camino. ${ }^{27}$ Durante el proceso de cristianización, muchos de ellos fueron consagrados a través de la incisión de cruces sobre sus inscripciones o mediante la colocación de estas cruces en su cima, actuaciones llevadas a cabo, en la mayoría de los casos, por los propios peregrinos. Al mismo tiempo, otros ejemplares fueron transformados en monumentos civiles o penales ( $\operatorname{rollos}^{28}$ y picotas ${ }^{29}$ ); tal es el caso del miliario de Viana do Castelo (Portugal) situado en la calzada romana que unía Braga con Astorga, utilizado primero como instrumento de justicia y posteriormente convertido en crucero.

Estas cruces de piedra no sólo marcaron la ruta jacobea en España sino que, fuera de nuestra Península, también señalizaron otras vías de peregrinación como la de Roma o Jerusalén. Aunque muchos de estos monumentos han desaparecido con el paso del tiempo o tras los movimientos iconoclastas, se conservan ejemplares como los situados a lo largo de la Vía Francígena ${ }^{30}$ que, atravesando la península italiana, llevaba a Roma. ${ }^{31}$

${ }^{25}$ Passini, J. 1993. El Camino de Santiago: Itinerario y núcleos de población, Madrid: Ministerio de Obras Públicas y Transportes; Soria y Puig A. 1993. El Camino a Santiago. Vías, estaciones y señales. Madrid: Ministerio de Obras Públicas y Transportes.

${ }^{26}$ Calzadas que coinciden con las rutas jacobeas.

${ }^{27}$ Término empleado para referirnos a las cruces sencillas y cruceros situados a lo largo del Camino de Santiago, que sirven de guía a los peregrinos.

${ }^{28}$ Columnas de piedra o hitos de carácter civil: insignia de una villa, delimitación de territorio, signos de jurisdicción o monumentos conmemorativos de concesión de villazgo.

${ }^{29}$ Las picotas eran columnas de piedra o hitos de carácter penal con remate de 4 ménsulas, donde se exponían los reos y ajusticiados a «deshonra».

${ }^{30}$ Camino medieval de peregrinación a Roma que partía desde Canterbury (Inglaterra).

${ }^{31}$ Stopani, R. 1999. «Le croci stradali: un elemento di sacralizzazione dello spazio, comune ai precosí delle tre peregrinazioni Maiores». Actas del III Congreso Internacional de Estudios Jacobeos: 331-340. 
ÓRDENES MONÁSTICAS EUROPEAS COMO DIFUSORAS DE CRUCES Y CRUCEROS. BENEDICTINOS, CISTERCIENSES Y PREMOSTRATENSES

La influencia del monacato en el desarrollo histórico de España ha sido muy importante, tanto en su forma inicial eremítica como en la cenobítica, principalmente a través de su papel evangelizador. De esta forma, todas las órdenes monásticas han contribuido de una manera u otra al florecimiento de la cultura, la religión, las artes, las ciencias e incluso la política de cada país.

Durante el periodo medieval, las órdenes monásticas que llegaron a la península Ibérica trajeron consigo influencias francesas y germanas que dejarán su huella en el arte de la época. Algunas de ellas influirán directamente en la ruta jacobea, como los benedictinos con sus hospederías y otras, vinculadas a las vías de comunicación como los premostratenses, serán las encargadas de levantar cruces en los caminos, entradas de pueblos, monasterios o ermitas.

\section{Los benedictinos y la introducción del arte europeo en la Península}

La Orden Benedictina o de San Benito fue fundada por Benito de Nursia en el año 529, formando la primera comunidad en Monte Casino (Italia). Se trataba de una orden basada en una economía cerrada para la comunidad, cuya organización se centraba en la abadía como punto de estabilidad y recogimiento. En un principio, sus únicas ocupaciones eran la oración y el trabajo - ora et labora-, incluyendo en este último grupo el cultivo de los campos y la labor intelectual de copistas y escritores.

El primer territorio peninsular donde se instaura esta orden es Cataluña, según consta en un documento del año $822,{ }^{32}$ pero no será hasta los siglos X y XI cuando se establecen en el resto de los reinos peninsulares. En un principio se trata de monasterios fundados por miembros de la nobleza puestos bajo las órdenes y la protección directa de Roma, lo que da muestra de la importancia que concedieron los soberanos tanto a los monasterios como a sus moradores. Pero el exceso de favor de reyes y nobles llevó a los monasterios cluniacenses hacia un grado de opulencia que supuso dejadez y ociosidad, comenzando su periodo de decadencia a final del siglo XII y que llegaría hasta el siglo XVIII. Por otro lado, la burguesía, llevada por un afán de ostentación, levantó cruceros, ermitas y monumentos religiosos con objeto de obtener el perdón divino, siguiendo modelos franceses traídos por estos monjes desde el otro lado de los Pirineos.

${ }^{32}$ Linage Conde, A. 1973. Los orígenes del monacato benedictino en la península Ibérica, vol. 3 : 80. León: CSIC, Centro de Estudios e Investigación «San Isidoro».

Hispania Sacra, LXV

131, enero-junio 2013, 7-28, ISSN: 0018-215-X, doi: 10.3989/hs.2013.001 
Esta orden monástica influyó de manera notoria tanto en aspectos históricos como artísticos de la época, pues con ella entran a través de los Pirineos las corrientes culturales y religiosas europeas, francesas y germánicas principalmente. Los monasterios catalanes, muy vinculados a los monasterios franceses, se convierten en centros de difusión de las culturas foráneas; en ellos se realizan copias de códices y se escriben libros, fundamentalmente litúrgicos, para difundirlos posteriormente. Pero este panorama cultural no es homogéneo en toda la península, la riqueza cultural de los monasterios, salvo algunas excepciones, ${ }^{33}$ va disminuyendo según avanzamos hacia el occidente peninsular.

La Orden Benedictina fundó numerosas hospederías a lo largo de la ruta jacobea, factor que contribuyó a impulsar las peregrinaciones durante los siglos centrales del periodo medieval. En esta época se consolidan las rutas europeas de peregrinación y especialmente la de Santiago, según hemos visto en el apartado anterior. Además de la influencia benedictina, hay que mencionar la del cristianismo celta proveniente de Irlanda a través de San Columbano, cuya orden se une a la de San Benito en Aniane (Francia). La orden así formada fundó numerosos conventos en Francia e Italia y cuyo ideal religioso celta, junto a su estilo artístico también celta, penetró en España a través del Camino de Santiago.

\section{La Orden Cisterciense y su proximidad al pueblo. Difusión de cruces y cruceros}

Según lo señalado anteriormente, durante el siglo XII Cluny pierde poder dentro de la estructura eclesiástica y se produce un nuevo cambio: surge una orden más adaptada al momento, la Orden del Císter o de San Bernardo. Sus ideales de pobreza y de eremitismo para los monasterios hacen que éstos se expandan por la Península de forma rápida. El sistema de aprovechamiento se basaba en el trabajo unísono de todos los miembros de la comunidad, los cuales sacralizaban al mismo tiempo el trabajo y la relación tierra-hombre. Las explotaciones rurales fueron aumentando la productividad y a principios del siglo XIII los monasterios cistercienses adoptan ya un sistema feudal y señorial: crecen sus dominios y propiedades y el trabajo de los monjes es realizado ahora por los campesinos que dependen directa (los de condición servil) o indirectamente (los de condición media con tierras arrendadas a los monjes) del monasterio para el que trabajan. Junto a la producción agrícola encontramos la ganadera, muy importante también, la vinícola e incluso la metalúrgica y minera.

\footnotetext{
${ }^{33}$ Destacan los monasterios riojanos de San Millán de la Cogolla y San Martín de Albelda, el burgalés de Santo Domingo de Silos, etc.
} 
En España, el Cister penetra en la cuarta década del siglo XII a través de los Pirineos; en un primer momento se expande mediante la afiliación de monasterios pertenecientes a monjes benedictinos o cluniacenses y más tarde fundando nuevos conventos con monjes venidos de abadías francesas. Con frecuencia se ha asociado la expansión del Císter en España con la fase de repoblación que sufre la Península tras la Reconquista durante el siglo XII y con el aumento de espacios de cultivo libres, lo que genera un aumento de la explotación de la tierra. Esta Orden monástica trajo consigo las influencias artísticas europeas, lo que queda reflejado en la erección de muchos cruceros en las proximidades de sus monasterios.

\section{La Orden Premostratense y su vinculación a las vías de comunicación}

La Orden Premostratense surge en el siglo XII en Coucy (Francia). Fundada por San Norberto en Premontré en el año 112 (Francia) siguiendo las reglas de San Agustín, se extendió por toda Europa, principalmente por las regiones centro-orientales. En la península Ibérica la primera fundación de que se tiene constancia es la del monasterio de Retuerta (Valladolid) en el año 1145, con una idea similar a la de los cistercienses en lo que a la explotación de las tierras se refiere pero, a diferencia de éstos, admitiendo el sistema feudal sin renunciar al trabajo directo de los miembros de la congregación. Los premostratenses cuentan con el apoyo de la nobleza y de los poderes políticos, participan en la vida económica de las ciudades y se encuentran muy vinculados a las vías de comunicación, en especial al Camino de Santiago.

Esta Orden se encargó de levantar numerosas cruces y cruceros en caminos, entradas de poblaciones y atrios de iglesias.

ÓRDENES MENDICANTES EUROPEAS COMO DIFUSORAS DE CRUCES Y CRUCEROS. DOMINICOS Y FRANCISCANOS

Las órdenes de monjes mendicantes ${ }^{34}$ nacen en un clima religioso de austeridad, vida pastoral renovada e ideales de reforma, con una sociedad en proceso de cambio en cuanto a modelos socio-políticos se refiere. Surgen en un periodo en el que todavía se mantiene en el mundo rural una organización política de acuerdo a los esquemas del feudalismo clásico, pero es a partir de esta fecha,

\footnotetext{
${ }^{34} \mathrm{Se}$ trata de aquellas órdenes religiosas, dentro del catolicismo, que han renunciado a toda propiedad y viven de la caridad. Las más importantes datan del siglo XIII y entre ellas podemos destacar los franciscanos (1209), dominicos (1216), carmelitas (1245) y agustinos (1256).
} 
con el auge de las comunicaciones, las ciudades y el comercio, cuando se cuestiona este sistema y surgen diferentes conflictos políticos y religiosos.

Las órdenes mendicantes - principalmente franciscanos y dominicosrevolucionaron el sistema monástico a través de la renovación del fervor popular y la lucha contra la herejía. Sus ideales se basaron en dos aspectos fundamentales: por un lado la renuncia a toda propiedad, viviendo sólo de la caridad de los fieles; por otro, la dedicación al apostolado directo con el pueblo. Para llevar a cabo su misión, situaron los conventos en medio de las poblaciones y no en zonas alejadas o aisladas como lo hacían las órdenes monásticas. Aconsejaron además, levantar cruces en las entradas de las poblaciones, en un primer momento sin imágenes, simplemente hincadas en el suelo o bien sobre gradas, en las que el brazo vertical inferior hacía las veces de columna; más tarde, ya en el siglo XIV, cruces góticas con la imagen de Cristo sobre columnas de piedra y alzadas sobre gradas. Este factor supuso la rápida propagación de estas construcciones, a lo que se unió el hecho de que las órdenes mendicantes, a diferencia del resto de los monjes - canónigos o clero secular- no estaban obligadas a residir en un lugar fijo, pues sustituyeron la antigua stabilitas loci de los benedictinos por el movimiento entre los distintos conventos. Al igual que esta última característica, junto al privilegio papal que les permitía predicar y confesar libremente por toda Europa, ayudó a la difusión de sus ideales de forma rápida por todo el territorio español.

A partir del siglo $\mathrm{xv}$, las órdenes mendicantes inculcaron en el pueblo el miedo a la muerte, entendida ésta como la posibilidad de una condena en el infierno y no, según se había hecho hasta entonces, como el inicio de una nueva vida. Después vinieron todas las controversias religiosas con el inicio de la Contrarreforma (s. XVI) y la petición de indulgencias. Con los jesuitas, a final del siglo XvI, surge la exaltación del Purgatorio, ${ }^{35}$ la devoción a las almas y la purificación de éstas a través de la oración en veredas o caminos (donde se suponía que vagaban las almas en pena errantes). La idea del Purgatorio quedó patente en el arte y especialmente en la expansión de los cruceros, muchos de ellos levantados para la petición de indulgencias y protección frente a la muerte. Con una idea parecida surgen también los petos de ánimas, lápidas exentas generalmente adosadas a un crucero y con la representación de las almas del

\footnotetext{
${ }^{35}$ La creencia en la purificación del alma después de la muerte es muy antigua. Así, las oraciones y los sufragios por los muertos ha sido una práctica habitual en la Iglesia desde los primeros tiempos. La podemos encontrar ya documentada en algunos textos de los Padres de la Iglesia, tanto oriental como occidental (Clemente de Alejandría, Orígenes, San Cipriano, Tertuliano, San Agustín, etc.) El Purgatorio como lugar de expiación de pecados y purificación de almas se define ya en el concilio ecuménico Lugdunense I, presidido por Inocencio IV en 1245.
} 
Purgatorio salvadas por San Francisco o la Virgen del Carmen; elementos cuya intencionalidad era demandar oraciones y limosnas para estas almas.

A diferencia de lo que ocurrió en la Península Ibérica, la idea del Purgatorio no se extendió en Bretaña, donde pensaban que después de la muerte sólo existía el Paraíso o el Infierno sin el tránsito del Purgatorio, motivo por el cual allí no vemos representaciones de ánimas, sino tan sólo de condenados. Esta es la principal diferencia entre muchos cruceros bretones y peninsulares, con representaciones de la muerte en dos sentidos diferentes: el Infierno frente al Purgatorio y los condenados frente a las almas. Es a partir de este siglo XVI cuando los cruceros se extienden con mayor profusión por el norte de la Península y por Bretaña. En nuestro territorio se levantaban a petición del pueblo, relacionados siempre con las indulgencias y la clemencia para los fallecidos; mientras que en Bretaña eran erigidos a petición del clero y la feligresía, para pedir por las calamidades que asolaban el mundo provocando la muerte.

Durante el siglo XVII desaparece prácticamente la idea del Infierno, para ser sustituida por la del Purgatorio y la idea de la salvación del alma a través de la oración. Es una época en la que la devoción por los muertos queridos y la esperanza de la salvación de sus almas a través del Purgatorio suponen la construcción de ermitas, capillas, iglesias y monasterios por parte de la población con un poder adquisitivo alto. Por su parte, los cruceros, levantados en caminos, atrios de iglesias o plazas, se erigían a petición de los más modestos, convirtiéndose de este modo en objetos de culto popular.

Con las órdenes mendicantes, los cruceros pasan de tener la antigua función de cristianizar lugares con reminiscencias paganas, a ser elementos destinados a la instrucción religiosa de los fieles.

\section{La Orden de los Dominicos. El estudio al servicio de la predicación}

Santo Domingo de Guzmán fundó la Orden de Predicadores en Tolosa el año 1207 y poco más tarde, Inocencio III reconoció la constitución del Ordo fratum praedicatorum, a pesar de lo acordado en el IV Concilio de Letrán para no fundar nuevas órdenes. La introducción de dicha orden en la Península se produce inicialmente por los reinos de Aragón, Castilla y León, creándose la provincia ${ }^{36}$ de España el año 1221 junto a las otras cuatro en las que se divide la orden dominica tras el Capítulo de Bolonia de ese mismo año. Se trata de una orden de carácter eminentemente clerical y acogida a las reglas de San Agustín,

\footnotetext{
${ }^{36}$ Denominación de cada una de las divisiones dependientes del gobierno central en la Orden de los Dominicos.
} 
con un modelo de capítulo propio de los cistercienses. Destaca por ser sus monjes grandes predicadores, al tiempo que eminentes teólogos con una gran formación dogmática. El carácter eminentemente apostólico, hizo que esta orden estuviera más próxima a las escuelas catedralicias que a las monásticas - todavía aferradas al sistema feudal - lo que llevó al nacimiento de las Universidades. Su forma de vida estaba basada en la austeridad y en la itinerancia, factor que favoreció de manera notoria el proceso evangelizador debido a su cercanía al pueblo. Los dominicos introdujeron en España influencias europeas - principalmente francesas - , que posteriormente divulgarán con su proceso de apostolado y con la fundación de numerosos conventos. Pero además, trajeron consigo modelos artísticos que quedarán reflejados en nuestro arte y por lo tanto en nuestros cruceros, en los que la influencia bretona deja importantes huellas.

La gran influencia que tuvo la orden de los dominicos en la difusión de los cruceros queda patente en las advocaciones a este santo que encontramos en muchos de ellos.

Llegados a este punto cabe destacar la gran difusión de los cruceros gracias a San Vicente Ferrer, dominico que inició su apostolado en Valencia, su ciudad natal, para pasar después a Aragón y Cataluña. Desde este último territorio se dirigiría hacia la Provenza, Italia, Saboya, Suiza y Holanda, para después volver de nuevo a Francia y divulgar su fe en Bretaña durante dos años. Desde allí traería a España la influencia francesa de sus cruceros. Así, visitó Santiago de Compostela en el año 1412, después de haber estado en Segovia, Salamanca y Zamora. Durante su viaje, aconsejó levantar cruces en las entradas de las ciudades, con la misma funcionalidad que las cruces de término valencianas erigidas después de la Reconquista. ${ }^{37} \mathrm{En}$ muchos de estos cruceros podemos apreciar una clara influencia de los calvarios bretones.

\section{La Orden de los Franciscanos y su devoción a la cruz}

La Orden Franciscana fue fundada por San Francisco de Asís en 1208 y aprobada por Inocencio III un año más tarde. Al igual que los dominicos, su vida giraba en torno a las predicaciones itinerantes, arropadas por una pobreza absoluta. Las enseñanzas de estos monjes se difundieron con mucha rapidez y a medida que pasaba el tiempo la orden crecía de forma considerable. En 1517, el papa León X los fraccionó en dos grupos de acuerdo a su estilo de vida y pastoral: los conventuales, a quienes estaba permitido poseer bienes en la comunidad y los observantes, seguidores fieles de la doctrina inicial de San Francisco.

\footnotetext{
${ }^{37}$ Burgoa Fernández, J. J. 2003: 57.
} 
La mística franciscana convirtió el crucifijo alegórico en un elemento con contenido dramático, es decir, transformó el dogma en drama y podríamos aventurarnos a decir que el culto a la cruz monumental fue instituido por los seguidores de San Francisco de Asís, que levantaron cruces delante de todos sus conventos. La expansión hacia el norte y occidente europeo de esta nueva mística se realizó a lo largo de los tres siglos siguientes a la fundación de la orden. En España este culto a la cruz monumental fue introducido por los monjes franciscanos en el siglo XVII con una función didáctica y de enseñanza religiosa, siendo las propias instituciones religiosas las que encargan la erección de dichos monumentos.

Del mismo modo, fueron franciscanos los encargados de introducir el Vía Crucis en España en el siglo XIII, aunque la verdadera difusión y proliferación del mismo, también llamado Camino de la cruz, tuvo lugar a partir del año 1686, fecha en la que Inocencio XI aprueba la concesión de indulgencias a través de la práctica de este camino (formado inicialmente por las 12 estaciones o paradas realizadas por Jesús camino del Calvario). Más tarde, en 1731, Clemente XIII fija las estaciones en 14 y permite su representación en todas las iglesias siendo bendecidas por los franciscanos. Este hecho supuso la erección de un elevado número de cruceros con objeto de marcar las 14 estaciones que forman el mismo.

Por otro lado, debemos también a los franciscanos el gran impulso que adquirió la religiosidad popular gracias a su proceso evangelizador en ciudades y pueblos, en el interior de los templos o en medio de plazas y campos. De este modo, fueron los encargados de levantar cruces y cruceros en las proximidades de los núcleos urbanos y de expandir esta costumbre por todo el territorio español. Debido a su carácter itinerante, también se les conocía como frailes in vía, y es importante señalar a este respecto, la posible vinculación de las vías de comunicación con la fundación de sus conventos (muchos de ellos coincidentes con antiguas rutas romanas). Los caminos se convierten en referentes de la difusión de sus ideales de pobreza y caridad, resultando ser auténticos ejes religiosos con innumerables cruces y cruceros protectores de los caminantes. Pero no sólo estas cruces se situaron en los caminos o en los límites de las poblaciones, sino también en las líneas divisorias de las feligresías controladas por su Orden, como queda patente en la población de Monforte de Lemos ${ }^{38}$ (Lugo) donde existía un crucero que marcaba el límite del convento de San Antonio, propiedad de los franciscanos. Según cuenta la tradición, cuando un feligrés deseaba ser enterrado en dicho cementerio, su cuerpo era trasladado hasta el crucero, punto donde se cedía a los franciscanos encargados de darle sepultura. Más tarde este

\footnotetext{
${ }^{38}$ Antiguamente Lemos.
} 
crucero se convertiría en punto de reunión y comercio, donde se intercambiaban cereales, maíz y legumbres. ${ }^{39}$

Las advocaciones de algunos cruceros a San Francisco, o la representación de monjes franciscanos en los mismos, confirma la influencia que la orden tuvo en la difusión de este arte popular. Podemos decir, por lo tanto, que la gran devoción de la orden francisca a la cruz fue decisiva en el desarrollo de los cruceros, principalmente como respuesta contra el protestantismo en el siglo XVII y por la gran devoción surgida a las ánimas del Purgatorio inculcada también por estos monjes.

\section{COMERCiO Marítimo. Vehículo PARA La INTROdUCCIÓN DE CRUCES Y CRUCERoS}

Muchos de los cruceros que se introdujeron en la península Ibérica desde Bretaña, Normandía y sur de Francia lo hicieron posiblemente por vía marítima, ${ }^{40}$ ya que la mayoría de ellos se encuentran en la costa norte y en el litoral mediterráneo. La semejanza de algunos cruceros gallegos y portugueses con los bretones hace suponer que el comercio marítimo con estas tierras trajera las influencias artísticas bretonas - y por consiguiente también normandas - al norte peninsular. Muestra de ello es el crucero de Guimaraes (Portugal) que, según datos aportados por Tomás Gonçalves, ${ }^{41}$ un mercader llamado Pero Esteves lo llevó desde Normandía a Portugal en el año 1342 para conmemorar la victoria de la Batalla del Salado. La influencia bretona en él es clara, pues el baldaquino que lo cubre y que le conferiría un origen francés, es de factura posterior al crucero. En tierras gallegas, concretamente en Santiago de Compostela, tenemos el crucero de Home-Santo con una cruz de factura similar a la de Guimaraes, lo que hace pensar en una misma procedencia.

Del mismo modo, el comercio con la costa sur francesa fue la consecuencia de la entrada de influencias artísticas procedentes de esta región hacia Cataluña y Levante a través del litoral mediterráneo. Muchas cruces francesas del siglo XIV y XV estuvieron cubiertas con un baldaquino apoyado sobre cuatro grandes columnas, hasta que en el siglo XVI, el abad Jehan de Saint Vertían prohibió que la señal del cristianismo fuera tapada, pues su única protección superior debía ser el cielo. Desde entonces, las cruces de esta región aparecen ya descubiertas. Sin embargo, es importante precisar que los cruceros bretones nunca

\footnotetext{
${ }^{39}$ Aira, F. 2003. «Las fiestas de San Antonio tienen su origen en el convento». La Voz de Galicia: 11 de junio.

${ }^{40}$ Además de las rutas terrestre ya mencionadas del Camino de Santiago.

${ }^{41}$ Gonçalves, A. T. 1925. «S. Gualter de Guimarães. Ensaio biográfico». Revista de Guimarães XXXV, 3: 201-206.
} 
presentaron esta techumbre, seguramente por influencia de las Islas Británicas. A pesar de las prohibiciones establecidas, algunos ejemplares se conservaron hasta el siglo XIX, época en la que desaparecen en su totalidad. Se tiene constancia de este hecho gracias a los dibujos y grabados realizados por Viollet le Duc y M. A. de Caumont. ${ }^{42}$

En lo que respecta a los cruceros de la costa mediterránea, el historiador S. Carreres Zacarés habla de la imposibilidad de que existieran ejemplares en tierra valenciana anteriores al año 1372, siendo las primeras cruces en llegar a la costa las del Maestrazgo de Montesa (Castellón) ${ }^{43}$ del siglo XIV, que después se extenderán hacia Valencia.

Vías tradicionales de comunicación como medio difusor de las cruces. Calzadas romanas en la Península Ibérica

Los caminos, como vías de comunicación, han existido desde épocas muy lejanas, pues ya el hombre del paleolítico practicaba la trashumancia a través de los mismos. La llegada de la civilización romana supuso la construcción de una importante red viaria de calzadas cuyo trazado coincidía, en algunos casos, con antiguos caminos pertenecientes a civilizaciones anteriores. A este respecto cabe señalar que la actual red de carreteras, iniciada en 1749, se basa fundamentalmente en la red viaria desarrollada durante los siglos XVI y XVII, con origen a su vez en las calzadas romanas. ${ }^{44}$

La documentación más antigua que conservamos sobre la distribución de estas calzadas en la península Ibérica - y sobre la que se han basado todos los estudios posteriores - data del siglo III; se trata del Itinerarium Provinciarum Antonini Augusti, documento donde consta una relación de itinerarios entre ciudades romanas y otros lugares de parada (mansio) con la indicación de la distancia que las separa de la anterior señalada en millia passumm. ${ }^{45} \mathrm{El}$ conjunto de la red de calzadas romanas de la península Ibérica sumaba un total de 9.000 millas con 34 itinerarios, según Antonino, y quedaba unida a las Galias por Roncesvalles, Somport y La Junquera, puntos de introducción en España de las corrientes artísticas, culturales y religiosas de Europa procedentes de Europa.

\footnotetext{
${ }^{42}$ Ferrá y Perelló, B. 1959. Techos artísticos en la Isla de Mallorca: cruces de piedra: 53-54. Palma de Mallorca: Mallorquina de Francisco Pons.

${ }^{43}$ Carreres Zacarés, S. 1927. «Cruces terminales en la ciudad de Valencia». Archivo de Arte Valenciano 13: 83-108.

${ }^{44}$ Uriol, J. I. 1985. «Las calzadas romanas y los caminos del siglo XVI». Revista de Obras Públicas 3237: 553-563.

${ }^{45}$ Medida romana de mil pasos equivalente a cinco mil pies romanos y a unos 1.480 metros.
} 
Las distancias entre ciudades estaban marcadas por los miliarios, elementos posteriormente cristianizados, por lo que esta red viaria se convierte en un importante medio de difusión de los cruceros, tanto por la conversión de antiguos miliarios como por la posibilidad de comunicación entre distintos puntos de la geografía. Los miliarios eran cipos de hasta dos metros de altura destinados a marcar las distancias entre ciudades; elementos considerados, en muchas ocasiones, como un paso entre el menhir y la marca kilométrica. Esta costumbre era únicamente romana, pues los griegos no marcaban en los caminos estas distancias, sino que colocaban unas piedras, conocidas como Hermes, destinadas a proteger a los viajeros y viandantes. En esta práctica podemos buscar también el origen simbólico de muchos cruceros situados a la vereda de los caminos y en las encrucijadas de los mismos.

Vías pecuarias: cañadas, cordeles, veredas y coladas

Se consideran vías pecuarias al conjunto de caminos destinados al tránsito del ganado trashumante. Atendiendo a la anchura e importancia de los mismos se dividen en cañadas, cordeles, veredas y coladas ${ }^{46}$ Estas vías adquieren diferente nomenclatura en función de la región donde se ubican; así, se denominan carreradas en Cataluña; cabañeras en Aragón; azagadores reales en Valencia y cañadas, galianas, veredas, cordones, cuerdas o cabañiles en Castilla. ${ }^{47}$

Independientemente del nombre que reciban, se trata de las rutas que llevaban el ganado desde los pastos del norte y centro peninsular (agostaderos), hasta los pastos de invierno del oeste o sur, invernaderos o extremos. Al ser esta trashumancia una marcha a extremos, desde la cabecera al extremo, desde las tierras frías del norte a las más cálidas del sur, podemos decir que la orientación de las cañadas es norte-sur.

En este entramado viario, cuyo origen podemos encontrarlo en los primitivos caminos de pastores nómadas, existen múltiples elementos complementarios que constituyen un rico patrimonio cultural: descansaderos, abrevaderos, puentes, majadas, contaderos o ranchos de esquileo. Estos elementos presentan, además, una vinculación directa con nuestras cruces, como es el caso del primero de ellos, los descansaderos, que se ubicaban en los cruces de caminos y cañadas, puntos en los que encontramos algunos cruceros destinados a proteger a los pastores e incluso a servirles de descanso en sus gradas de piedra. A estos elementos complementarios de las cañadas habría que añadir las dehesas situadas

\footnotetext{
${ }^{46}$ Medidas establecidas por la Mesta y que se mantienen hasta la Ley de 27 de junio de 1974.

${ }^{47}$ Klein, J. 1990. La Mesta. Estudio de la historia económica española 1273-1836: 19. Madrid: Alianza Universal.
} 
junto a algunas cabañas, que constituían grandes extensiones de prados para el pasto junto a encinares, rebollares y fresnedas, en medio de las cuales también encontraremos cruces y cruceros para la bendición de animales.

Este movimiento de ganado llevó a la reglamentación de la actividad ganadera y alcanzó su época de máximo esplendor en los siglos XV y XVI. En Castilla y León tiene su origen en la Edad Media cuando en 1273, Alfonso X el Sabio constituyó el Honrado Concejo de la Mesta, organización con gran poder que agrupaba a los propietarios y pastores de ganados de ovejas merinas. ${ }^{48}$ Aunque hay que mencionar al respecto que, en época visigótica ya existía cierta regularización en el pastoreo, como podemos ver en el Código de Eurico ${ }^{49}$ y el Fuero Juzgo, ${ }^{50}$ documentos donde se describe de forma general este movimiento trashumante. ${ }^{51}$ También Las Partidas ${ }^{52}$ de Alfonso X hablan del dominio público de los caminos y su aprovechamiento.

Por lo que concierne a la marcación viaria, su origen se remonta a la prehistórica. Las primeras señalizaciones de los caminos consistieron en una serie de estelas e hitos ${ }^{53}$ como la estela de Solana de Cabañas, en Logrosán (Cáceres), en que aparece la representación grabada de un guerrero junto a otros objetos y que se ha interpretado como el personaje protector o guardián del territorio que delimita este elemento. ${ }^{54}$

Más tarde aparecerán las marcaciones celtíberas de los framontanos ${ }^{55}$ pastores que señalizaban los caminos por los que transitaban, con unos hitos en forma de animales, los llamados verracos, ${ }^{56}$ entre los que podemos mencionar los conocidos ejemplares abulenses: el Verraco de la Cogotas en Cardeñosa y los «toros» de Guisando. Estas figuras tendrían la misión de proteger el ganado, los campos y los caminos por los que transitaban los rebaños. ${ }^{57}$

\footnotetext{
${ }^{48}$ García Martín, P. 1994. Por los caminos de la trashumancia: 15-36. Valladolid: Junta de Castilla y León.

${ }^{49}$ Texto legal visigodo promulgado por el rey Eurico entre el año 466 y 481 . También conocido como Código de Tolosa.

${ }^{50}$ Conjunto de leyes elaborado por Fernando III en 1241 y que constituye una traducción del Liber Iudiciurum del año 654, de época visigoda.

${ }^{51}$ García Martín P. 1991. Cañadas, Cordeles y Veredas: 24. Valladolid: Junta de Castilla y León.

${ }^{52}$ ALFONSO X EL SABIO, Las Partidas, Part. $3^{\text {a }}$. Tit. 39, Leyes $6^{\text {a }}$ y $7^{\text {a }}$.

${ }^{53}$ Ruiz-Gálvez, M; Galán Domingo, E. 1991. «Las estelas del suroeste como hitos de vías ganaderas y rutas comerciales». Trabajos de prehistoria 48: 257-273.

${ }^{54}$ Galán Domingo, E. 1995. «La estela de Solana de Cabañas» en García Blanco, A.(coord.), Creencias y ritos funerarios: 10-11. Madrid: Museo Arqueológico de Madrid.

${ }^{55}$ Pastores celtíberos dedicados a la ganadería trashumante.

${ }^{56}$ Figuras de cerdos, labradas en piedra de forma muy tosca, mal llamadas toros por el pueblo. Cronológicamente pertenecen a la cultura céltica. Por ejemplo los «toros» de Guisando (Ávila), las tres cabezas de Gerión, el ídolo de Mikeldi (Vizcaya), etc.

${ }^{57}$ Paredes Guillén V. 1888. Historia de los framontanos celtíberos. Plasencia: El Cantón Extremeño.
} 
Con el devenir de la historia estas cañadas permanecieron señalizadas mediante hitos o mojones, con el objeto de servir de guía a los ganaderos y evitar agresiones en su trazado original. El cristianismo, por su parte, sembró de cruces los caminos para la protección de los caminantes, al igual que aconteció con las vías pecuarias, en cuyo recorrido se fueron levantando numerosas cruces y cruceros para proteger a los pastores y sus ganados. Muchos de estos ejemplares han llegado hasta nuestros días en su emplazamiento original, junto a las cañadas.

Hasta aquí venimos hablando de la distribución de las vías pecuarias en la península Ibérica, pero es necesario mencionar que esta disposición de caminos no es exclusiva de nuestro territorio. En efecto, dentro de la estructura viaria romana existían las llamadas calles pastorum, caminos de la Italia meridional por donde se desplazaba el ganado de un pastizal a otro, pasando después a ser las tratturi (que unían montañas y llanuras) con los bracci (veredas más pequeñas que partían de estos últimos. De igual forma, en Francia existían los denominados chemins de transhumance, vías para ganado que iban desde el Mediodía francés hasta los Alpes y viceversa.

\section{Caminos carreteros, de herradura y recueros}

Los tratados sobre caminería de principios del siglo XIX hacen ya una distinción entre los caminos que permitían el tránsito del tráfico rodado, denominados caminos carreteros y aquellos a cuyo través era imposible dicho paso, llamados de herradura o recueros. ${ }^{58}$ Estos últimos son conocidos desde época medieval, como lo demuestra el hecho de que en 1219 existiera ya la Cofradía de los recueros, dedicada al transporte de materias primas con animales, organización que poseía una serie de privilegios otorgados por el rey Fernando III.

Tras el largo periodo rural de la Edad Media, nace un nuevo concepto de economía: las ciudades y se potencia la economía mercantil, el comercio y la carretería como medio de transporte. Es a partir de este momento cuando desde la corona se exige el cuidado y conservación de los caminos y vías de transporte. Así, en el año 1497, los Reyes Católicos obligan a todos los Concejos a mantener los caminos en perfectas condiciones y otorgan un privilegio a la Real Cabaña de Carreteros ${ }^{59}$ gracias al cual estos quedaban exentos del pago de tributos y se les permitía viajar libremente por los pueblos, empleando los pastos para el ganado y la madera para leña o para reparar las carretas.

\footnotetext{
${ }^{58}$ Personas encargadas de guiar un conjunto de animales de tiro que van juntos, conocidos como recuas.

${ }^{59}$ Congregación de profesionales dedicados a las mercancías con carretas.
} 
Con el tiempo, la Real Cabaña de Carreteros, Trajineros, cabañiles y sus derramas $^{60}$ abarcaría todo el reino de Castilla, quedando dividida en tres hermandades o comarcas: Burgos-Soria, Ávila y Cuenca. Esta asociación surgió en puntos con abundantes pastos para el ganado y pinares para madera, productos que constituían una de las principales materias primas de transporte. Dicha organización llevaba implícito un entramado muy bien estructurado con objeto de controlar la administración, la cual se ordenaba y organizaba según el marco nacional, provincial y comarcal en tres estatus con subniveles locales.

La Corona continuó, durante un largo periodo, favoreciendo la labor de los carreteros a través de cédulas reales y numerosos privilegios. De este modo, Carlos I facilitó las comunicaciones mejorando todos los caminos; más tarde, Felipe $\mathrm{V}$ promulgó una Real ordenanza para la construcción de nuevos caminos, estableciendo una distribución radial con centro en la Puerta del Sol de Madrid.

Llegado el siglo XVIII existía una gran diferencia entre los sistemas de transporte del interior, únicamente terrestres, y los de las zonas costeras, con un importante auge económico gracias al transporte por vía marítima. A partir de este momento y durante todo el siglo XIX, la carretería inicia un periodo de decadencia, que durará hasta principios del siglo xx, con un momento decisivo tras la Constitución de 1812, cuando son eliminados todos los privilegios de los carreteros. Sin embargo, en las zonas rurales del interior de la meseta el sistema de transporte continuó siendo el mismo hasta épocas muy recientes, debido principalmente a la compleja orografía del terreno, que imposibilitaba el uso de otros sistemas.

El conjunto de caminos carreteros y de herradura, coincidentes en muchos casos con otras vías de comunicación, estaban protegidos por cruces y cruceros a lo largo de su recorrido.

\section{ConClusiones}

La principal conclusión que podemos extraer del presente trabajo es que las primeras cruces hincadas fueron las de las Islas Británicas como resultado de la evolución de los menhires y que más tarde se extendieron por Francia, España e Italia gracias a los monjes irlandeses. Dentro ya de la península Ibérica, las distintas órdenes monásticas y el movimiento de gentes a lo largo de las diversas vías de comunicación supusieron el medio de difusión de estos elementos artísticos.

\footnotetext{
${ }^{60}$ Denominación de la Real Cabaña de Carreteros a partir del año 1626.
} 
También es importante destacar que el carácter etnográfico que presentan estas cruces de piedra permite analizar las diferentes formas de vida de la población, sus usos y costumbres. Así, la funcionalidad de estos conjuntos monumentales viene determinada por la ubicación de los mismos.

Por último mencionar que el estudio de todos los aspectos involucrados en la erección de las cruces y los cruceros situados en caminos, campos o plazas resulta fundamental a la hora de abordar los nuevos planes de dinamización del entorno rural, proyectos donde debe quedar insertado nuestro rico patrimonio cultural.

\section{BIBLIOGRAFÍA}

Aira, F. 2003. «Las fiestas de San Antonio tienen su origen en el convento». La Voz de Galicia: 11 de junio.

ALFONSO X EL SABIO, Las Partidas, Part. $3^{\mathrm{a}}$. Tit. 39, Leyes $6^{\mathrm{a}}$ y $7^{\mathrm{a}}$.

Alonso Romero, F. 1991. Santos e barcos de pedra: 55-57. Vigo: Xerais.

Brown, G. B. 1921. The Arts in Early England: The Ruthwell and Bewcastle Crosses. New York: Dutton.

Burgoa Fernández J. J. 2003. Los cruceros, el patrimonio etnográfico y el arte popular: 107. La Coruña: edicios do Castro.

Carreres Zacarés, S. 1927. «Cruces terminales en la ciudad de Valencia». Archivo de Arte Valenciano 13: 83-108.

Díaz y Díaz, M. 1965. «La literatura jacobea anterior al Códice Calixtino». Compostellanum 10, 4: 283-305.

Ferrá y Perelló, B. 1959. Techos artísticos en la Isla de Mallorca: cruces de piedra: 53-54. Palma de Mallorca: Mallorquina de Francisco Pons.

Galán Domingo, E. 1995. «La estela de Solana de Cabañas» en García Blanco, A. (coord.), Creencias y ritos funerarios: 10-11. Madrid: Museo Arqueológico de Madrid.

García García, A. 1986. «Ecclesia Britoniensis». Estudios Mindonienses 2: 121-134.

García Martín P. 1991. Cañadas, Cordeles y Veredas: 24. Valladolid: Junta de Castilla y León.

García Martín, P. 1994. Por los caminos de la trashumancia: 15-36. Valladolid: Junta de Castilla y León.

Gonçalves, A. T. 1925. «S. Gualter de Guimarães. Ensaio biográfico». Revista de Guimarães XXXV, 3: 201-206.

Henry, F. 1930. «Les origines de l'iconographie irlandesa». Revue Archéologique XXXII: 89-109. 
Kingsley Porter, A. 1935. The crosses and culture of Ireland. New Haven: Yale University Press.

Klein, J. 1990. La Mesta. Estudio de la historia económica española 1273-1836: 19. Madrid: Alianza Universal.

Linage Conde, A. 1973. Los orígenes del monacato benedictino en la península Ibérica, vol. 3: 80. León: CSIC, Centro de Estudios e Investigación «San Isidoro».

Moralejo A. 2004. Liber Sancti Jacobi, trad. Santiago de Compostela: Xerencia de Promocion do Camiño de Santiago.

Paredes Guillén V. 1888. Historia de los framontanos celtíberos. Plasencia: El Cantón Extremeño.

París, G. 2000. Légendes du Moyen Age: 31-41. Barcelona: MRA.

Passini, J. 1993. El Camino de Santiago: Itinerario y núcleos de población, Madrid: Ministerio de Obras Públicas y Transportes.

Rodríguez Castelao, A. 1984. As cruces de pedra na Galiza: 20-28. Facsímil de 1950. Vigo: Galaxia.

Ruiz-Gálvez, M; Galán Domingo, E. 1991. «Las estelas del suroeste como hitos de vías ganaderas y rutas comerciales». Trabajos de prehistoria 48: 257-273.

Soria y Puig A. 1993. El Camino a Santiago. Vías, estaciones y señales. Madrid: Ministerio de Obras Públicas y Transportes.

Stokes, M. 2004. Early Christian Art in Ireland. Montana: Kessinger Publishing.

Stokes, W. 1893. «The voyage of the Hui Corra». Revue Celtique XIV: 61.

Stopani, R. 1999. «Le croci stradali: un elemento di sacralizzazione dello spazio, comune ai precosí delle tre peregrinazioni Maiores». Actas del III Congreso Internacional de Estudios Jacobeos: 331-340.

Uriol, J. I. 1985. «Las calzadas romanas y los caminos del siglo XVI». Revista de Obras Públicas 3237: 553-563. 